\title{
Neuroleptic malignant syndrome associated with COVID-19 vaccination
}

\author{
Takahiko Nagamine ${ }^{1}$ (D)
}

Received: 22 November 2021 / Accepted: 10 December 2021 / Published online: 17 December 2021

() The Author(s), under exclusive licence to Canadian Association of Emergency Physicians (CAEP)/ Association Canadienne de Médecine d'Urgence (ACMU) 2021

Keywords Neuroleptic malignant syndrome $\cdot$ COVID-19 vaccination $\cdot$ Immunostimulatory effect

Dear editor,

Neuroleptic malignant syndrome is a fulminant and lifethreatening disorder that occurs in patients treated with antipsychotic medication. Although the pathophysiology of neuroleptic malignant syndrome is not fully understood, it involves a central hypodopaminergic state and an acute phase reaction as an immune response [1]. We report a case of this syndrome after COVID-19 vaccination. Written consent was obtained from the patient.

A 61-year-old Japanese woman was brought to the emergency room with high fever and disorientation. She had developed schizophrenia 35 years ago and had recently been treated with risperidone $6 \mathrm{mg} /$ day. The day before admission, she received an intramuscular injection of $0.3 \mathrm{~mL}$ of Comirnaty $^{\circledR}$, a mRNA vaccine against SARS-CoV-2. However, $20 \mathrm{~h}$ after the vaccination, she was unable to walk due to muscle pains all over her body and called an ambulance. On arrival, she was confused with a high fever of $40{ }^{\circ} \mathrm{C}$, tremors in her upper limbs, and muscle stiffness all over her body. She was sweating, had tachycardia of 134/ min and elevated blood pressure of $168 / 102 \mathrm{mmHg}$. A quick blood test in the emergency room revealed a creatine kinase $>5000 \mathrm{IU} / \mathrm{L}$, and complete blood count was remarkable for an elevated white blood cell $>10,000 / \mathrm{mm}^{3}$. COVID19 antigen test was negative. Chest X-ray, urine analysis, and blood culture showed no abnormalities. Her symptoms and blood tests clearly met the diagnostic criteria for neuroleptic malignant syndrome [2]. Risperidone was discontinued, and

Takahiko Nagamine

tnagamine@outlook.com

1 Department of Emergency Medicine and Psychiatric

Internal Medicine, Sunlight Brain Research Center, 4-13-18

Jiyugaoka, Hofu, Yamaguchi 747-0066, Japan she was admitted to the high care unit for systemic management with massive infusion of fluids. Lead-pipe rigidity improved one week after admission. On the 10th day of hospitalization, her creatine kinase level decreased to 2932 IU/L and she was able to walk.

COVID-19 infection increases the risk of developing neuroleptic malignant syndrome [3], but there are few reports of neuroleptic malignant syndrome associated with COVID19 vaccination [4]. SARS-CoV-2 binds to the angiotensinconverting enzyme 2 (ACE2) receptors and enters the body. There are many ACE2 receptors in the brain, and it has been speculated that the mechanism by which COVID19 infection causes neuroleptic malignant syndrome may be via ACE2 receptors [5]. Although the mRNA vaccine promotes the synthesis of viral spike proteins, they do not activate ACE2 receptors, and thus vaccine-induced neuroleptic malignant syndrome is a different mechanism than neuroleptic malignant syndrome caused by COVID-19 infection. After vaccination, immune-transducing cells called dendritic cells begin to work, and synthesizing proinflammatory cytokines [6]. Elevated levels of proinflammatory interleukins such as IL- 6 and TNF- $\alpha$ have been reported in neuroleptic malignant syndrome [7]. Thus, the immunostimulatory effect of the vaccine may cause the pathogenesis of neuroleptic malignant syndrome.

Funding No funding was provided.

\section{Declarations}

Conflict of interest The author has no conflicts of interest relevant to the content of this article. 


\section{References}

1. Anglin RE, Rosebush PI, Mazurek MF. Neuroleptic malignant syndrome: a neuroimmunologic hypothesis. CMAJ. 2010;182(18):E834-8.

2. Strawn JR, Keck PE Jr, Caroff SN. Neuroleptic malignant syndrome. Am J Psychiatry. 2007;164(6):870-6.

3. Kajani R, Apramian A, Vega A, Ubhayakar N, Xu P, Liu A. Neuroleptic malignant syndrome in a COVID-19 patient. Brain Behav Immun. 2020;88:28-9.

4. Alfishawy M, Bitar Z, Elgazzar A, Elzoueiry M. Neuroleptic malignant syndrome following COVID-19 vaccination. Am J Emerg Med. 2021;S0735-6757(21):00117.
5. Jafari Khaljiri H, Jamalkhah M, Amini Harandi A, Pakdaman H, Moradi M, Mowla A. Comprehensive review on neuro-COVID-19 pathophysiology and clinical consequences. Neurotox Res. 2021;39(5):1613-29.

6. Palmieri B, Vadala' M, Palmieri L. Immune memory: an evolutionary perspective. Hum Vaccin Immunother. 2021;17(6):1604-6.

7. Kamińska T, Szuster-Ciesielska A, Wysocka A, MarmurowskaMichałowska H, Dubas-Slemp H, Kandefer-Szerszeń M. Serum cytokine level and production of reactive oxygen species (ROS) by blood neutrophils from a schizophrenic patient with hypersensitivity to neuroleptics. Med Sci Monit. 2003;9(7):C71-5. 